\title{
Correlations of sialic acid with glycated hemoglobin A1c and glycemia in postmenopausal women with type- 2 diabetes mellitus
}

\author{
OCTAVIAN GABRIEL OLARU ${ }^{1}$, GIANINA IOANA CONSTANTIN ${ }^{2}$ and CATALINA MONICA PENA ${ }^{2}$ \\ ${ }^{1}$ Department of Obstetrics and Gynecology, 'Carol Davila' University of Medicine and Pharmacy, 040292 Bucharest; \\ ${ }^{2}$ Department of Biology of Aging Research, 'Ana Aslan’ National Institute of \\ Gerontology and Geriatrics, 011241 Bucharest, Romania
}

Received November 11, 2020; Accepted December 11, 2020

DOI: $10.3892 /$ etm.2021.9717

\begin{abstract}
For women in the postmenopausal period, age-related changes in the hormonal status are associated with a higher risk for type-2 diabetes and its complications. The tissue injury caused by diabetic vascular complications can induce a release of sialic acid (SA) into the general circulation leading to increased levels. The present study is a cross-sectional single center study of 77 women in the postmenopausal period. The subjects selected for the study were divided into two groups: i) The control group, which included postmenopausal women without type-2 diabetes mellitus $(n=27)$; and ii) a group of postmenopausal women diagnosed with type-2 diabetes $(n=50)$. By analyzing how the serum values of SA were correlated with glycemia and glycated hemoglobin in the subjects with diabetes, it was determined that both parameters exhibited a strong positive correlation $(\mathrm{P}<0.0001)$ in the group with type-2 diabetes. Therefore, SA may be considered as a potential marker for the screening, diagnosis or prognosis of type-2 diabetes for postmenopausal women.
\end{abstract}

\section{Introduction}

Diabetes mellitus is a group of chronic metabolic diseases characterized by high blood sugar levels induced by defects in insulin secretion and/or insulin sensitivity $(1,2)$. For women in the postmenopausal period, changes in the hormonal status

Correspondence to: Dr Octavian Gabriel Olaru, Department of Obstetrics and Gynecology, 'Carol Davila' University of Medicine and Pharmacy, 10 Bucur Street, 040292 Bucharest, Romania

E-mail: octavian_olaru@umfcd.ro

Abbreviations: WHO, World Health Organization; $\mathrm{Hb} \mathrm{Alc}$, glycated hemoglobin; SA, sialic acid; TSA, total sialic acid; BMI, body mass index; SD, standard deviation; DCCT, Diabetes Control and Complications Trial; UKPDS, United Kingdom Prospective Diabetes Study; IDF EUR, European Chapter of the International Diabetes Federation

Key words: sialic acid, diabetes mellitus type-2, glycemia, glycated hemoglobin, post menopause can result in imbalances in glycemic metabolism, which may lead to type-2 diabetes and the associated complications. Thus, postmenopausal woman have a higher risk for type- 2 diabetes mellitus, independently and additionally to aging (3).

Type-2 diabetes mellitus, also known as non-insulindependent diabetes, is significantly associated with a 10 -year reduced life expectancy (4). In 2016, the World Health Organization (WHO) estimated that diabetes was the seventh leading cause of death worldwide. In addition, diabetes is associated with a significant decrease in the quality of life and significant morbidity due to severe complications (5-7). The frequency and severity of complications increase with the duration of the disease and patient age, and the most common complication is neuropathy followed by nephropathy and retinopathy $(8,9)$.

Unlike type-1 diabetes, type-2 diabetes mellitus is preceded by a period of prediabetes (glucose intolerance), which consists of a period of $\sim 7$ years between the onset of the disease and the onset of symptoms, during which time microvascular and macrovascular complications can occur. The later the disease and its complications are detected, the more complex and expensive the treatment is (10-12).

Regarding diagnostic and monitoring tools, it is known that measuring blood glucose levels allows the assessment of the current status of carbohydrate metabolism in diabetic patients at the time of blood sampling. By contrast, the determination of glycated hemoglobin ( $\mathrm{Hb} \mathrm{A} 1 \mathrm{c})$ provides a retrospective estimate of glycemic status, independent of circadian rhythm, diet and other transient fluctuations in blood glucose. Having been used for a long time exclusively as a marker for glycemic control, $\mathrm{Hb}$ Alc has recently been adopted by the WHO as a diagnostic test (13).

Sialic acid (SA) (or $N$-acetylneuraminic acid), is an essential component of glycolipids and glycoproteins. Some glycoproteins form the terminal component of numerous acute-phase proteins, such as $\alpha_{1}$-antitrypsin, haptoglobin, $\alpha_{1}$-antichymotrypsin and orosomucoid. In addition, SA acts as a co-factor of a number of cell receptors and is positively associated with the majority of the serum acute phase reactants (14).

It has been hypothesized that tissue injury caused by diabetic vascular complications stimulates local cytokine secretion from cellular infiltrates, such as macrophages and endothelial cells (15). This injury induces an acute phase 
Table I. Biochemical and clinical parameters of the study groups.

\begin{tabular}{|c|c|c|c|c|}
\hline $\begin{array}{l}\text { Biochemical and } \\
\text { clinical parameters }\end{array}$ & Control group $(n=27)$ & $\begin{array}{l}\text { Type- } 2 \text { diabetes } \\
\text { mellitus group }(n=50)\end{array}$ & t-value & P-value \\
\hline Age, years & $63.74 \pm 8.50$ & $69.9 \pm 7.99$ & $\mathrm{t}=-3.155$ & $\mathrm{P}<0.01$ \\
\hline Glucose, mg/dl & $94.25 \pm 9.12$ & $145.48 \pm 52.73$ & $\mathrm{t}=-4.991$ & $\mathrm{P}<0.00001$ \\
\hline Total cholesterol, mg/dl & $210.96 \pm 35.88$ & $239.38 \pm 45.87$ & $\mathrm{t}=-2.788$ & $\mathrm{P}<0.01$ \\
\hline HDL-cholesterol, mg/dl & $54.58 \pm 15.67$ & $45.71 \pm 13.93$ & $\mathrm{t}=0.793$ & $\mathrm{P}=0.214$ \\
\hline LDL-cholesterol, mg/dl & $129.71 \pm 26.30$ & $146.93 \pm 42.22$ & $\mathrm{t}=-1.435$ & $\mathrm{P}<0.01$ \\
\hline Triglycerides, mg/dl & $117.14 \pm 38.41$ & $176.3 \pm 96.15$ & $\mathrm{t}=-3.059$ & $\mathrm{P}<0.01$ \\
\hline BMI, $\mathrm{kg} / \mathrm{m}^{2}$ & $25.64 \pm 3.83$ & $30.92 \pm 5.65$ & $\mathrm{t}=-2.158$ & $\mathrm{P}<0.05$ \\
\hline $\mathrm{Hb} \mathrm{A} 1 \mathrm{c}, \%$ & $5.65 \pm 0.41$ & $7.33 \pm 1.02$ & $\mathrm{t}=-1.667$ & $\mathrm{P}<0.05$ \\
\hline $\mathrm{TSA}, \mathrm{mg} / \mathrm{dl}$ & $76.64 \pm 7.63$ & $94.25 \pm 21.51$ & $\mathrm{t}=-4,104$ & $\mathrm{P}<0.001$ \\
\hline
\end{tabular}

Data are presented as mean \pm standard deviation. BMI, body mass index; Hb A1c, glycated hemoglobin; TSA, total sialic acid.

response with the release of acute phase glycoproteins such as SA from the liver into general circulation, leading to their increased levels $(16,17)$. Thus, determination of the level of SA in the blood may be useful for the evaluation of patients with prediabetes or diabetes.

The aim of the present study was to investigate the correlation of SA levels with HbAlc and glycemia values in postmenopausal women with type- 2 diabetes mellitus depending on age.

\section{Patients and methods}

The cross-sectional single center study was conducted on 77 women in the postmenopausal period (age range, 55-87 years). All subjects were inpatients admitted to 'Ana Aslan' National Institute of Gerontology and Geriatrics (NIGG), Bucharest, Romania. The study period was between June 2018 and May 2019.

All women that agreed to participate provided written informed consent. The study protocol was approved by the NIGG Research Ethics Committee and all procedures performed in the present study were in accordance with the Helsinki Declaration with its later amendments and with the ethical standards of the National Research Committee of Romania.

Female subjects were included in the present study if they adhered to the following inclusion criteria: i) Age, $\geq 55$ years; ii) postmenopausal status; iii) an adequate understanding of the Romanian language; iv) able to communicate and cooperate (e.g. without Alzheimer's disease in the advanced stage or a cognitive disease or advanced disability); and v) able to provide informed consent. The exclusion criteria were as follows: Age, <55 years; ii) not postmenopausal; iii) unable to communicate; and iv) the presence of a pre-existing major, severe or disabling pathology, such as dementia, a severe physical disability, neoplasia, an inflammatory syndrome of other causes, stroke, cardiac failure, kidney failure or cirrhosis.

The subjects selected for the study were divided into two groups: i) The control group, which included postmenopausal women without type-2 diabetes mellitus ( $n=27)$; and ii) a group of postmenopausal women diagnosed with type-2 diabetes $(n=50)$. The age range of all participants was 55-87 years, with a mean age of $63.74 \pm 8.50$ years for the control group and $69.9 \pm 7.99$ years for the type- 2 diabetes mellitus group.

Data collection. Venous blood samples were collected in the morning after an overnight fasting of $\geq 12 \mathrm{~h}$, by venous puncture in vacuum tubes. The samples were maintained at room temperature within $1 \mathrm{~h}$ of collection, and then centrifugated at $1,000 \mathrm{x} \mathrm{g}$ for $20 \mathrm{~min}$ at room temperature, aliquoted and refrigerated at $-70^{\circ} \mathrm{C}$ until analysis.

Serum total sialic acid (TSA) was assayed using a colorimetric enzymatic method as previously described (18), which is a standard Ehrlich's method and colorimetric assay, using reagents and chemicals with an analytical grade that were purchased from Sigma-Aldrich; Merck KGaA. According to this method, the supernatant of serum containing SA chemically reacts with the Ehrlich's reagent and produces a colorimetric reaction that is quantitatively measured using a spectrophotometer. This procedure is based on the release of bound SA by heating with $5 \%$ perchloric acid. After cooling and brief centrifugation, the supernatant was heated for $15 \mathrm{~min}$ with Ehrlich's reagent at $100^{\circ} \mathrm{C}$. Subsequently, the absorbance of the color developed in the sample was measured at $565 \mathrm{~nm}$, and the serum concentration of SA was expressed in $\mathrm{mg} / \mathrm{dl}$ (18).

Serum determinations of blood glucose (glycemia) and $\mathrm{Hb} \mathrm{A} 1 \mathrm{c}$ were performed using a turbid metric method and diagnostic products of Thermo Fisher Scientific, Inc., with a Konelab 301 SC auto analyzer.

Menopausal status and hormone replacement therapy (HTR) use were recorded. Menopause was defined as the point when a woman no longer has menstrual periods for $\geq 12$ months and the postmenopausal period is the stage after menopause (19).

Statistical analysis. All calculated data are presented as the mean \pm standard deviation. Means were compared with Student's t-test using Excel 7.0 software (Microsoft Corp.). Pearson's correlation coefficients (r) were calculated to evaluate the correlations between TSA, glycated HbA1c and glycemia. $\mathrm{P}<0.05$ was considered to indicate a statistically significant difference. 

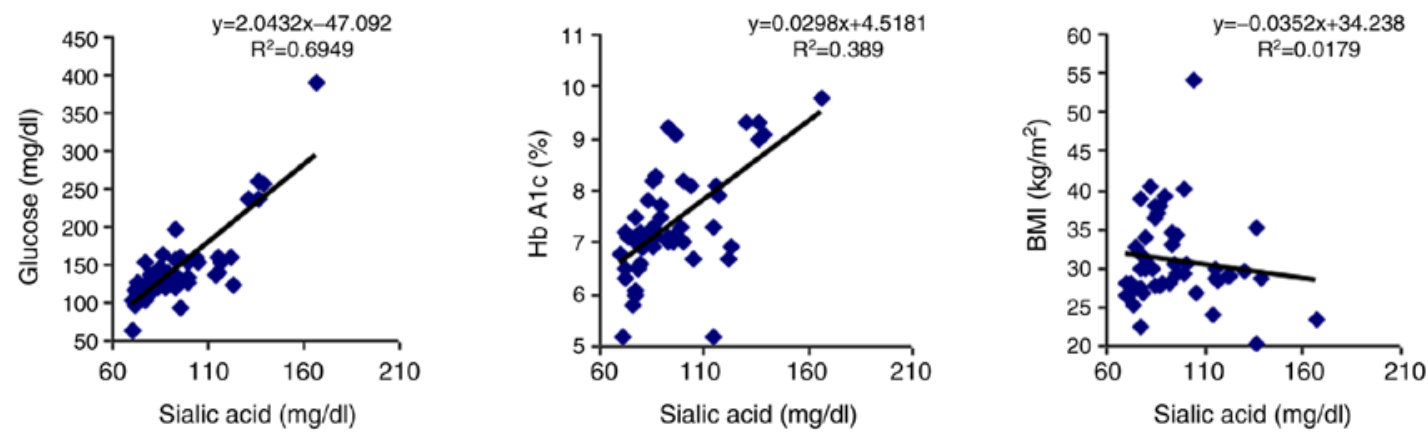

Figure 1. Type-2 diabetes group Pearson's correlation (r) analysis between individual values of serum sialic acid and serum glucose, glycated hemoglobin (Hb Alc) and body mass index (BMI).
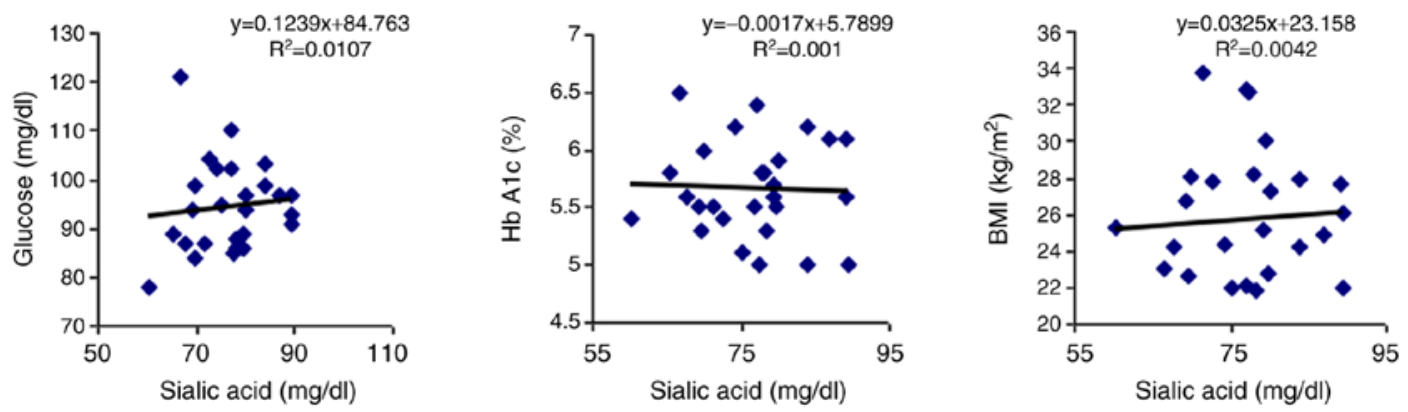

Figure 2. Control group Pearson's correlation (r) analysis between individual values of serum sialic acid and serum glucose, glycated hemoglobin (Hb Alc) and body mass index (BMI).

\section{Results and Discussion}

The burden of diabetes worldwide has captured the academic interest in the field of health for a long duration. Typically, concerns include the costs associated with the disease and the complications that ensue from this condition, which have led to interventions designed by policy makers and health care authorities that are meant to prevent the disease (20).

Because most people diagnosed with type-2 diabetes are elder individuals, this condition among the elderly is a growing public health issue. In addition, the situation is further complicated by the fact that geriatric patients usually have multiple associated pathologies and special related physiological characteristics.

This fact justifies the important budgetary efforts of many countries, including Romania, for the development of diabetes research and monitoring programs, of which laboratory investigations should be an integral part. According to the latest data of the European Chapter of the International Diabetes Federation (IDF EUR), 463 million people have diabetes worldwide and $>59$ million individuals in the EU region have diabetes; by 2045 this is expected to rise to 68 million (21). The prevalence of diabetes shows an increasing trend for all age groups, specifically due to increased obesity, unhealthy eating and physical inactivity (22).

Romania is one of the 57 countries of the IDF EUR, and the diabetes prevalence (\% of population aged 20 to 79 years) in this country was reported to be $6.9 \%$ in $2019(21,23)$. According to the PREDATORR study 'Prevalence of diabetes mellitus and prediabetes in the adult Romanian population',
Table II. Correlations of serum TSA with serum glucose, $\mathrm{Hb}$ $\mathrm{A} 1 \mathrm{c}$ and $\mathrm{BMI}$ in the type-2 diabetes group.

\begin{tabular}{lcc}
\hline Parameters analyzed & r-value & P-value \\
\hline Serum TSA and serum glucose & $r=0.833$ & $\mathrm{P}<0.00001$ \\
Serum TSA and Hb A1c & $r=0.623$ & $\mathrm{P}<0.00001$ \\
Serum TSA and BMI & $\mathrm{r}=0.133$ & $\mathrm{P}=0.35400$
\end{tabular}

BMI, body mass index; Hb A1c, glycated hemoglobin; TSA, total sialic acid.

Table III. Correlation analyses between serum TSA and serum glucose, $\mathrm{Hb} \mathrm{A} 1 \mathrm{c}$ and $\mathrm{BMI}$ in the control group.

\begin{tabular}{lcc}
\hline Parameters analyzed & r-value & P-value \\
\hline Serum TSA and serum glucose & $r=0.103$ & $\mathrm{P}=0.607$ \\
Serum TSA and Hb A1c & $r=0.031$ & $\mathrm{P}=0.875$ \\
Serum TSA and BMI & $\mathrm{r}=0.064$ & $\mathrm{P}=0.748$ \\
\hline
\end{tabular}

BMI, body mass index; Hb A1c, glycated hemoglobin; TSA, total sialic acid.

in 2017 in an adult population of $14,382,000$ there were $1,785,300$ cases of diabetes in adults aged $20-79$ years, with a prevalence of $12.4 \%$, and this number is expected to decrease to $1,246,000$ in 2045 (24). 
By analyzing the statistical data presented in Table I, it was determined that laboratory clinical parameters observed in the study and the BMI exhibited higher mean values in the group of patients with type-2 diabetes compared with the control group, with one exception of HDL level which was higher in the control group. This parameter was the only one with a protective role and a higher mean value in the control group compared with the type-2 diabetes group.

By analyzing how the serum values of SA are correlated with glycemia and $\mathrm{Hb} \mathrm{A} 1 \mathrm{c}$ in the subjects with diabetes, it was observed that both parameters exhibited a strong positive correlation ( $\mathrm{P}<0.0001$; Table II and Fig. 1).

In the present study, TSA values were not correlated with BMI, therefore the results obtained in the present study were not consistent with those of a study published in 2013 by Rajappa et al (25), who reported that TSA exhibited a significant positive correlation with BMI $(\mathrm{P}<0.01)$, with TSA levels being elevated in individuals with obesity.

For comparison, the correlations of TSA with the three parameters were analyzed with the help of a linear regression model, and it was observed that in the control group there were no correlations with any of the parameters (Table III and Fig. 2).

In conclusion, the present study demonstrated that there are strong positive correlations between the serum values of TSA, glycemia and $\mathrm{Hb}$ A1c in subjects with diabetes. However, serum TSA levels were not correlated with BMI. Therefore, SA may be considered as a potential marker for the diagnosis or screening of type-2 diabetes in postmenopausal women.

\section{Acknowledgements}

Not applicable.

\section{Funding}

No funding was received.

\section{Availability of data and materials}

All data generated or analyzed during this study are included in this published article.

\section{Authors' contributions}

OGO contributed to the study design, the establishment of the patient selection criteria, the formation of the study groups, analysis and interpretation of the patient data, and the writing of the article. GIC contributed to the establishment of the study groups, analysis and interpretation of the patient data, and the writing of the article. CMP contributed to the establishment of the study groups, and analysis and interpretation of the data used for the article. All authors read and approved the manuscript and agree to be accountable for all aspects of the research in ensuring that the accuracy or integrity of any part of the work are appropriately investigated and resolved.

\section{Ethics approval and consent to participate}

The Ethics Committee of 'Ana Aslan' National Institute of Gerontology and Geriatrics scrutinized and approved the study protocol (PV3/12.03.2019). Each subject was informed and signed an consent form. All procedures performed in this study were in accordance with the ethical standards of the National Research Committee of Romania and with the Helsinki declaration and its latter amendments.

\section{Patient consent for publication}

Not applicable.

\section{Competing interests}

The authors declare that they have no competing interests.

\section{References}

1. American Diabetes Association: Diagnosis and classification of diabetes mellitus. Diabetes Care 32 (Suppl 1): S62-S67, 2009.

2. Gradinaru D, Khaddour H, Margina D, Ungurianu A, Borsa C, Ionescu C, Prada GI, Usher J and Elshimali Y: Insulin-leptin axis, cardiometabolic risk and oxidative stress in elderly with metabolic syndrome. Exp Clin Endocrinol Diabetes 126: 445-452, 2018.

3. Paschou SA, Anagnostis P, Pavlou DI, Vryonidou A, Goulis DG and Lambrinoudaki I: Diabetes in menopause: Risks and management. Curr Vasc Pharmacol 17: 556-563, 2019.

4. Melmed S, Polonsky K, Larsen PR and Kronenberg HM (eds): Complications of Diabetes Mellits. In: Williams Textbook of Endocrinology. 12th edition. Philadelphia, Elsevier/Saunders, pp1371-1435, 2011.

5. Meneilly GS and Tessier D: Diabetes in elderly adults. J Gerontol A Biol Sci Med Sci 56: M5-M13, 2001.

6. Shivananda Nayak B, Duncan H, Lallo S, Maraj K, Matmungal V, Matthews F, Prajapati B, Samuel R and Sylvester P: Correlation of microalbumin and sialic acid with anthropometric variables in type 2 diabetic patients with and without nephropathy. Vas Health Risk Manag 4: 243-247, 2008.

7. Krentz AJ and Bailey CJ: Oral antidiabetic agents: Current role in type 2 diabetes mellitus'. Drugs 65: 385-411, 2005.

8. Arambewela MH, Somasundaram NP, Jayasekara HB, Kumbukage MP, Jayasena PM, Chandrasekara CM, Fernando KR and Kusumsiri DP: Prevalence of chronic complications, their risk factors, and the cardiovascular risk factors among patients with type 2 diabetes attending the diabetic clinic at a tertiary care hospital in Sri Lanka. J Diabetes Res 2018: 4504287, 2018.

9. Balcangiu-Stroescu AE, Tanasescu MD, Diaconescu A, Raducu L, Balan DG. Mihai A, Tanase M, Stanescu II and Ionescu D: Diabetic nephropathy: A concise assessment of the causes, risk factors and implications in diabetic patients. Rev Chim 69: 3118-3121, 2018.

10. Balan DG, Balcangiu-Stroescu AE, Tanasescu MD, Diaconescu A, Raducu L, Mihai A, Tanase M, Stanescu II and Ionescu D: Nutritional intervention in patients with diabetic renal disease-a brief presentation. Rev Chim 69: 4078-4082, 2018.

11. Mandita A, Timofte D, Balcangiu-Stroescu AE, Balan D, Raducu L, Tanasescu MD, Diaconescu A, Dorin D, Cosconel CI, Stoicescu SM and Ionescu D: Treatment of high blood pressure in patients with chronic renal disease. Rev Chim Buchar 70: 993-995, 2019.

12. Ionescu D, Niewada M and Czech M: PDB63 Liraglutide in the treatment of type 2 diabetes Mellitus-economic evaluation in Romanian setting. Value Health 13: A295, 2010.

13. Hare MJL, Shaw JE and Zimmet PZ: Current controversies in the use of haemoglobin A1c. J Intern Med 271: 227-236, 2012.

14. Lindberg G, Råstam L, Gullberg B, Lundblad A, Nilsson-Ehle P and Hanson BS: Serum concentrations of total sialic acid and sialoglycoproteins in relation to coronary heart disease risk markers. Atherosclerosis 103: 123-129, 1993.

15. Totan A, Balcangiu-Stroescu AE, Imre MM, Miricescu D, Balan D, Stanescu II, Ionescu D, Timofte D, Tanasescu MD and Greabu M: XOR-possible correlations with oxidative stress and inflammation markers in the context of diabetic kidney disease. Rev Chim 70: 1396-1398, 2019.

16. World Health Organization: Diabetes. https://www.who. $\mathrm{int} /$ news-room/fact-sheets/detail/diabetes. Accessed June 26, 2020. 
17. Borsa C, Gradinaru D, Margina D, Prada GI and Peña CM Receptor of advanced glycation end products and cardiovascular risk in elderly with type 2 diabetes mellitus. J Biol Res Boll Soc Ital Biol Speriment 90: 81-86, 2017.

18. Olaru OG, Constantin GI and Pena CM: Variation of total serum sialic acid concentration in postmenopausal women. Exp Ther Med 20: 2455-2459, 2020.

19. Takahashi TA and Johnson KM: Menopause. Med Clin North Am 99: 521-534, 2015.

20. Little RR, Rohlfing CL and Sacks DB; National Glycohemoglobin Standardization Program (NGSP) Steering Committee. Status of hemoglobin A1c measurement and goals for improvement: From chaos to order for improving diabetes care. Clin Chem 57: 205-214, 2011.

21. Diabetes NSW: International Diabetes Federation 'Life for a Child' Programme. https://www.idf.org/our-network/regionsmembers/europe/members/154-romania.html. Accessed June 26, 2020.

22. World Health Organization Europa, Diabetes, Data and statistics. http://www.euro.who.int/en/healthtopics/noncommunicable-diseases/diabetes/data-and-statistics. Accessed June 26, 2020.
23. Druica E, Goschin Z and Băicus C: Regional socio-economic factors influencing diabetes incidence: The case of Romania. East J Eur Stud 9: 87-109, 2018

24. Mota M, Popa SM, Mota E, Mitrea A, Catrinoiu D, Cheta DM, Guja C, Hancu N, Ionescu-Tirgoviste C, Lichiardopol R, et al: Prevalence of diabetes mellitus and prediabetes in the adult Romanian population: PREDATORR study. J Diabetes 8: 336-344, 2016

25. Rajappa M, Ikkruthi S, Nandeesha H, Satheesh S, Sundar I, Ananthanarayanan PH and Harichandrakumar KT: Relationship of raised serum total and protein bound sialic acid levels with hyperinsulinemia and indices of insulin sensitivity and insulin sensitivity and insulin resistance in non-diabetic normotensive obese subjects. Diabetes Metab Syndr 7: 17-19, 2013.

(i) 1 This work is licensed under a Creative Common Attribution-NonCommercial-NoDerivatives 4.0 International (CC BY-NC-ND 4.0) License. 